\title{
EL SEGON MONESTIR DE JONQUERES I EL MOLÍ D'EN CARBONELL
}

\author{
MARia Mercè Costa i Paretas \\ Arxiu de la Corona d'Aragó \\ (Barcelona)
}

\begin{abstract}
L'orde militar de Sant Jaume va tenir a Barcelona un dels seus més importants monestirs femenins: Santa Maria de Jonqueres. Un grup de dames, al voltant de Maria de Terrassa, va obtenir del bisbe Berenguer de Palou, el primer d'abril de 1214 , la parròquia de Sant Vicenç de Jonqueres, prop de Sabadell. La comunitat d'aquell primer monestir va gaudir llargament de la protecció pontifícia i de la reial i va anar adquirint diverses propietats en el Vallès i també al territori de Barcelona, entre Sant Andreu de Palomar i Sant Martí de Provençals.

Precisament a la part més occidental del terme de Sant Martí, en un terreny elevat que formava el coll anomenat de la Celada, el rei Jaume I va disposar la construcció d'un segon monestir que seria la segona residència de les dames de Jonqueres. I precisament ací volem començar la nostra petita història.
\end{abstract}

Segons Carreras Candi, la Barcelona del segle XIV es dividia en quatre quarters o barris, rodejats de muralla: el del nord-est era el de Sant Pere o de la Celada; allà mateix, fora la muralla, hi havia el coll de la Celada, conegut ja amb aquest nom a les darreries del segle $\mathrm{X}$. A la vora del coll, el 1343, hi fou construïda una creu de terme anomenada Creu de la Celada o del Portal Nou, o també de Sant Francesc de Paula quan davant la creu s'hi instal-là un monestir dedicat a aquell sant, el 1578. Consta que aquest convent de frares Mínims es trobava a la part forana del Portal Nou. La creu fou enderrocada i reconstruïda diverses vegades; per això, segons

"Anuario de Estudios Medievales". 28 (1998) 
les circumstàncies, el poble l'anomenava Creu nova o Creu trencada. Va desaparèixer el 1719, quan en el seu lloc hi fou construït el Fort Pius, com una avançada de la Ciutadella, més allunyat que aquesta de la muralla del Portal Nou. El fort fou enderrocat entre el 1868 i el 1869, però el seu nom ha subsistit fins al nostre temps per al barri on s'havia establert. Hom parla també d'una capelleta que depenia de la parròquia de Sant Pere i que, el 1902, es trobava al Fort Pius, al carrer de Sardenya tocant al de Casp, prop d'on hi havia hagut el convent de Mínims i la creu'. Com a conclusió, creiem que podríem situar el coll de la Celada en el territori que va des del cap del carrer del Portal Nou fins al de Marina, sense passar més amunt del que ara és la Gran Via de les Corts Catalanes.

El territori era travessat pel rec Comtal, que corria en direcció al mar. El seu curs era puntejat per una sèrie de molins fariners, principalment d'aigua, ja des dels segles X i XI. El rec i els molins pertanyien a la Corona, que en rebia els seus drets ${ }^{2}$. Duran i Sanpere diu que la Creu trencada, segons un dels contractes de la seva reconstrucció, es trobava fora el Portal Nou, "deçà lo molí d'en Carbonell"3.

El rei Jaume I va donar llicència a un notari barceloní, Pere Carbonell, per edificar un molí cuber al coll de la Celada i li assenyalà la forma de prendre l'aigua necessària: primer, des del rec que duia l'aigua amb la qual Romeu Durfort regava la seva terra, fins al torrent d'Alviana; després prendria l'aigua del mateix torrent, de la que es regaven les terres del canonge Ramon de Montseny, la faria tornar a la sèquia reial dels molins de Barcelona i des d'allà la conduiria cap al lloc on volia fer el molí, i finalment aniria a retrobar el torrent esmentat. Per tot això, Carbonell havia de pagar al rei un cens anual de 50 morabetins, el dia de Nadal. Però quan el molí ja era construït, el rei va moure una qüestió a ell i a tots els altres que havien fet molins nous en aquells indrets, per raó d'un cert perjudici (no explicat) que el monarca en rebia; i per sentència va prohibir el funcionament de tots aquells molins. Carbonell era ara el perjudicat per les moltes

'F. Carreras CANDI, La ciutat de Barcelona, "Geografia General de Catalunya", Barcelona (1916), pp. 315, 385, 411 nota $1125,628,773,901,935,959$ nota 2524, 1035.- G FELIU, La toponímia del Pla de Barcelona al segle X , "El Pla de Barcelona i la seva historia", Actes del I Congrés d'Història del Pla de Barcelona, Barcelona 1984, p. 106.

'Carreras Candi, op. cit., pp. 295, 398-399, 659.

${ }^{3}$ A. DuRAn I SANPERE, Barcelona i la seva Historia. La formació d'una gran ciutat, Barcelona 1972, p. 613. 
despeses que havia fet en la construcció i va recórrer al rei, tot suplicant, a més, que, en lloc de fer-li pagar el cens, prengués la meitat dels guanys del molí, deduïdes abans les despeses de material i de personal. El rei s'hi avingué, revocà la sentència només pel que tocava al molí d'en Carbonell i li confirmà la possessió a perpetuïtat, el 10 d'agost de 1267. Si volia, Pere podia vendre el molí, restant sempre vigent el dret que el rei hi tenia ${ }^{4}$.

Però fou el rei mateix el qui, el 13 d'abril de 1270, va donar per sempre a Pelayo Pérez Correa, mestre de l'orde de Sant Jaume, la seva part i domini sobre el molí, amb la condició que el mestre o els seus successors fessin edificar vora el molí un monestir per a les monges de Jonqueres, que no volien viure més en el terreny despoblat de Sant Vicenç i desitjaven acostar-se més a la ciutat; la condició per a elles era la de residir efectivament en aquest segon monestir. I si no era construit dins dos anys, el rei recuperaria tot el seu dret. Al cap d'un mes, el batlle de Barcelona, Guillem Gruny, donava possessió del molí a Elisenda de Mura, priora de Jonqueres, tal com l'havia rebut del rei el mestre Pelayo Correa ${ }^{5}$.

El bisbe de Barcelona, Arnau de Gurb, el 6 de març de 1271, donà llicència al canonge Berenguer de la Pedra, procurador i administrador en nom de Pelayo Correa, per edificar una casa o cases per a residència de cavallers i dames de l'orde, com també de conversos, germans i familiars de tots ells; en especial, pensava en les dames, que podrien viure, deia ell, en el mateix indret de Jonqueres o bé traslladar-se a un altre lloc si així ho preferien. No sembla que l'edifici fos ja construit. De totes maneres, devia ser-ho ja dins el termini dels dos anys fixat pel rei. La que és ben certa, però, és la llicència que el rei donà a les monges, el 10 de desembre de 1273 , per a prendre de la sèquia del molí l'aigua que necessitessin, exclusivament per a regar l'hort que hi tenien a la vora. Amb tota seguretat, doncs, la comunitat ja vivia en el seu segon monestir6. L'any següent, una nova priora, Saurina de Cort, va sol-licitar i obtenir de l'infant Pere,

${ }^{4} \mathrm{ACA}$ (=Arxiu de la Corona d'Aragó), ORM (=Ordes Religiosos i Militars), U (=sèrie Universitat), pg. (=pergamins), J. 428 (amb numeració provisional, pendents de classificació definitiva); RP (=Reial Patrimoni), Batllia, vol. 445, fol. 42v.- J.M. MADURELL, Els molins a Catalunya en temps de Jaume I (Notes documentals), "Jaime I y su época. X Congreso de Historia de la Corona de Aragón. Comunicaciones 3, 4 y 5", Zaragoza, 1982, p. 169.

${ }^{5} \mathrm{ACA}, \mathrm{RP}$, Batllia, vol. 445, fol. 41; ORM, U, pg. J.317.- M.P. IBÁÑEZ, La fundación y primera época del monasterio de Junqueras (1212-1389), "Anuario de Estudios Medievales", 11 (Barcelona, 1981), pp. 363-382, doc. núm. 5.

${ }^{6}$ ACA, ORM, U, pg. J.378, J.320. 
primogènit reial, la confirmació de la donació feta pel rei a l'orde de Sant Jaume ${ }^{7}$

Malgrat tot, la ubicació del monestir no va resultar gaire agradosa per a les monges. La proximitat, potser, de la sèquia produïa una humitat gens aconsellable. Van passar alguns anys i fou el rei Alfons II el qui, veient que aquell lloc era "multum infirmus", va concedir a la priora Guillema de Sant Romà, el 1289, tot i aprovant la donació de Jaume I i sense oblidar la condició d'aquesta pel que feia a la situació de l'edifici, la llicència per edificar el monestir en un altre lloc, a Barcelona o en el seu territori; però els conservava la meitat del dret reial sobre el molí i un altre dret sobre la seva aigua. Uns drets que foren seguidament objecte d'una reclamació de la priora perquè només havien cobrat la meitat del que els pertocava, ja que els batlles reials no els volien donar la resta ${ }^{8}$.

El nou canvi de residència no fou tampoc massa fàcil. Probablement la mort del rei ho va ajornar tot. El 25 de maig de 1293, Jaume II autoritzava el trasllat a la priora Guillema, en termes semblants als del seu germà Alfons, i accentuava el fet de trobar-se el monestir en un lloc poc idoni per a la salut de les monges. No era tampoc gaire lluny de la Llacuna, terra pantanosa o d'aiguamolls. Seguia vigent el respecte als drets sobre el molí. I com que necessitaven abans vendre les cases i possessions corresponents al segon monestir, els afegí, el rei, una altra llicència per a vendre o establir l'aigua que passava per un forat d'una certa mola, tal com els l'havia donada Jaume I per a regar l'horta'.

Pere Carbonell ja havia mort i el seu fill Guillem seguia tenint una quarta part del molí a cens del monestir de Jonqueres. Una sentència arbitral ho va reconèixer, el 16 de juny de 1294 , en determinar que el monestir podia seguir rebent l'aigua del rec del molí per a regar les seves terres, però, com que el dret de pas havia causat perjudicis a Carbonell, havien de pagar-li a ell 20 sous barcelonins. La part de Carbonell la volia comprar el batlle de Barcelona actuant en nom del rei com si aquest en tingués el domini. Però la priora Margarida de Togores el requerí per tal que abandonés el seu propòsit, ja que el domini el tenia solament el monestir. Després, la priora va comprar a Carbonell aquella quarta part per 3.000 sous

\footnotetext{
${ }^{7} A C A$, ORM, U, pg. J.319, J.322; RP, Batllia, vol. 445, fol. $41 \mathrm{v}$.

${ }^{8}$ ACA, ORM, U, pg. J.425, J.457; RP, Batllia, vol. 445, fol. 42.

${ }^{9}$ ACA, ORM, U, pg. J.429, J.316; RP, Batllia, vol. 445, fols. 69v, 67.
} 
i la va vendre en alou, per 5.000 sous, a Pere Barceló, el 14 de març de 1296. Pere Barceló va prendre possessió de la seva part i, l'onze d'abril, va prometre a la comunitat que si, dins el termini de tres anys, li pagaven 3.000 sous dels 5.000 del preu de venda, els la restituiria; si no, passats aquells anys, els pagaria els 2.000 sous restants del preu. Segurament, n'havia pagat només tres mil en el moment de l'adquisición ${ }^{10}$.

És molt possible que aquells negocis no tinguessin un resultat efectiu. De Barceló no se'n parla més. En canvi, Guillem Carbonell, el 24 d'octubre següent, com a procurador dels marmessors del seu pare, va donar possessió a la priora de Jonqueres de dos terços de l'esmentada part que li havien venut. L'altre terç el van comprar els executors testamentaris de Guillem Colrat, els quals van instituir una capellania per tal que, tres dies a la setmana, fos celebrada una missa per aquest difunt així com pel rei Alfons II, a l'altar de Sant Joan i Santa Maria Magdalena del monestir de Jonqueres; al prevere celebrant li assignaren diverses parts de censals, entre ells aquell terç procedent dels Carbonell, per un total de 2.000 sous ${ }^{\prime \prime}$. Guillem Colrat era el qui, juntament amb Guillem de Cortada, el 1294, havia pagat a Guillem Carbonell, en nom del monestir, els 20 sous, d'acord amb la sentència referent al dret de pas.

Tornant a les vendes fetes pels marmessors del difunt Pere a les monges, hi ha encara dos terços de mig morabetí censal que es rebia del convent de monges Menors pel dret de pas de l'aigua del rec Comtal a través de l'alou d'en Carbonell; dos terços d'un altre mig morabetí censal que pagaven els hereus de Pere d'Església i de Bernat de Cabanes, moliners, també per un dret de pas; i dos terços de tres censals sobre una terra que ara tenia Ramon Jaume prop del molí. Pels documents de l'època, sembla que el convent, el 1296, ja s'havia traslladat perquè hi ha alguna al·lusió al molí com a proper a l'antic monestir de Jonqueres. I situen el molí en el coll de la Celada, en el camí que va des del coll cap a Sant Andreu de Palomar' ${ }^{12}$.

\footnotetext{
${ }^{10}$ ACA, ORM, U, pg. J.194, J.335, J.443, J.440, J.325.

"ACA, ORM, U, pg. J.445, J.324.

${ }^{12}$ ACA, ORM, U, pg. J.324.- CARRERAS CANDI (op. cit., p. 1024 nota 2697) diu que la carretera de Sant Andreu, el 1886, s'anomenava carretera de Ribes i anava des del Fort Pius fins al pas a nivell del tren. Per les notícies de situació que hem donat al començament, gairebé diriem que el segon monestir devia trobar-se entre els carrers de Sardenya, Marina, Casp i carretera de Ribes.
} 
Tot això devia formar part de les mesures que havia pres la comunitat en previsió del seu trasllat al nou monestir, el tercer i definitiu, a l'interior de la ciutat de Barcelona, exactament al triangle que formava la muralla, sota la que al cap de molts segles seria la plaça d'Urquinaona, amb un carrer i un torrent que ben aviat prendrien el nom de Jonqueres. No obstant, segons altres referències, el trasllat devia tenir lloc el 1300. En efecte, el 22 de juliol de 1301, la priora i convent establien a Bernat d'Olzina i la seva muller Elisenda una casa amb un hort, molt a prop, deien, del monestir recentment construit ${ }^{13}$.

No podem aclarir, per ara, per quina raó des dels primers anys del sege XIV el rei disposava del seu dret a una part del molí i d'un altre dret sobre l'aigua. Dos germans freners barcelonins, Ramon i Bernat Sa-Torra, el 1305, van demanar llicència per a treure de la sèquia del molí i de la fibla o presa anomenada de Santa Anna l'aigua necessària per a regar dues mujades i mitja de terra que tenien en el lloc de la Llacuna. En aquella ocasió el monarca va encomanar al batlle de Barcelona, Tomàs Gruny, i a l'escrivà Bertran Des-Vall que ho permetessin, si veien que era veritablement una cosa útil i que no disminuirien, per això, els drets reials sobre els molins de Barcelona. Més endavant, el 1311, els fou fet un nou establiment de l'aigua del molí, a un cens anual de quatre sous per cada mujada de terra ${ }^{14}$.

Successivament, el rei Jaume II obligà la part i dret reial que tenia en el molí a Simó de Vic. Quan aquest morí, ho recuperà del seu hereu Simonet. Llavors ho donà, amb caràcter vitalici, al domèstic reial Pere Calvet, el 8 de març de 1324 , amb la previsió de recuperar-ho novament a la mort d'aquest ${ }^{15}$.

Aquesta vegada les coses van anar per un altre camí. La reina Elisenda havia començat a fer construir el monestir de Pedralbes i va veure que les seves monges necessitarien un molí fariner. El rei no trobà altra solució que cedir-li a perpetuitat la seva part del molí d'en Carbonell i el dret a rebre l'aigua del rec Comtal. La cessió fou feta el 9 de març de 1327, però es realitzaria quan morís Calvet o bé, en vida d'ell, si arribaven a un acord. Si per alguna raó el monestir no s'acabava de construir, tornaria al rei tot el que els havia donat. L'abadessa i el convent de Pedralbes van fer

\footnotetext{
${ }^{13} \mathrm{ACA}, \mathrm{ORM}, \mathrm{U}$, pg. J.183.

${ }^{14} \mathrm{ACA}, \mathrm{C}$ (=Cancelleria), reg. 203, fol. 83; reg. 208, fol.68.

${ }^{15} \mathrm{ACA}, \mathrm{C}$, reg. 225, fol. 189.
} 
l'acord amb Calvet i van obtenir plenament el dret sobre el molí. Jaume II va morir el novembre següent i, el 8 de gener de 1328, el seu fill Alfons III va confirmar la donació ${ }^{16}$.

No podem tampoc explicar-nos el fet que, al cap de 40 anys, torni a aparèixer el molí en mans de les monges de Jonqueres. Pel que hem vist, van tenir un plet amb les monges de Pedralbes. Per compromís de les dues parts fet el 26 d'abril de 1367, l'havien de resoldre Berenguer Vives, de Barcelona, i Francesc Botella, prior de Santa Eulàlia del Camp. Però els qui actuaren finalment com a àrbitres foren Jaume de Vallseca i Guillem de Puig, llicenciats en lleis. La sentència, donada el 5 de juny següent, declarava que el domini directe i alodial del molí pertanyia al monestir de Jonqueres, el qual havia de posar-hi un moliner, sense demanar per això el consens del convent de Pedralbes; les rendes i fruits es partirien per la meitat entre els dos monestirs, deduïdes abans les despeses de material, obres, etc., i el moliner juraria al procurador de Pedralbes que compliria aquestes seves obligacions. Pedralbes hi posaria un guarda per tal d'evitar possibles fraus en la partició. Si es descobria un frau, Jonqueres havia de canviar el moliner. El 1371 va aparèixer un cert Andreu Cartró, el qual declarava haver comprat o arrendat els drets del molí al monestir de Pedralbes. El procurador i ecònom de Jonqueres, el prevere Pere Roqueta, el requerí per tal que abandonés el molí, ja que, segons la sentència arbitral, Pedralbes només hi podia tenir un guarda i el moliner no li havia de donar compte de res $^{17}$.

En aquell temps, el rei Pere III tenia una gran preocupació per la construcció de les drassanes de Barcelona. Entre altres coses, faltava la coberta de l'edifici, però també faltaven diners per acabar les obres. L'obrer major era el barceloní Pere Terreny (o Terrer), també conseller de la ciutat. El rei va fer un acord amb ell i els altres consellers, el 1378, sobre les contribucions que es podrien dedicar a aquells treballs. I per començar, ell mateix es va vendre els drets sobre alguns dels seus molins, cosa que sens dubte no fou suficient. Tant era així, que l'obrer major va presentar al rei un projecte minuciós que feia referència a diversos molins. Semblava que la millora prevista per a ells i per a les drassanes passava per enderrocar els molins d'en Carbonell (que, segons que també sembla, en aquella època

\footnotetext{
${ }^{16} \mathrm{ACA}, \mathrm{C}$, reg. 229, fols. 264-265; reg. 473, fols. 85-86; RP, Batllia, vol. 445, fol. 12.

${ }^{17} \mathrm{ACA}, \mathrm{ORM}, \mathrm{U}, \mathrm{pg} . \mathrm{J} .444, \mathrm{~J} .441$.
} 
devien ser dos, segurament en un mateix casal), una volta fos pagat allò que corresponia als monestirs de Pedralbes i de Jonqueres que en tenien la senyoria. Deixant de banda els punts del projecte relatius a altres molins, hom preveia que l'aigua de la sèquia dels d'en Carbonell, que corria cap a la Llacuna, tornaria, un cop enderrocats, al rec reial (és a dir, el Comtal) i permetria la construcció d'un molí draper prop dels molins reials del Soler jussà i dos de bladers al casal dels molins de Sant Pere, i d'altres per a esmolar o per a serrar fusta en els molins de la Mar. I després de tot, hi hauria mil florins d'or o més per a l'obra de la drassana. El rei, el 15 d'abril de 1383, va acceptar la proposta però va encarregar a l'obrer que, juntament amb alguns prohoms experts, ho examinés tot personalment i procedís segons el que ells li aconsellessin; si el projecte es duia a terme, podria pagar el degut als monestirs i cobrar els florins d'or per a la drassana. I en cas que algú mogués un nou plet, l'hauria de resoldre Jaume de Vallseca i fer-hi justícia. No sabem el que va resultar d'aquesta qüestió; fos com fos, el 1387 les drassanes ja tenien feta la coberta ${ }^{18}$.

Tant si els molins es van enderrocar com si no i si, en el primer cas, van ser reconstruïts, el cert és que el monestir de Jonqueres va conservar-ne el domini i, durant el segle XV i més tard, es preocupà d'arrendar "el" molí d'en Carbonell i de fer-hi les obres que fossin necessàries. El primer arrendament que coneixem el va fer la priora Francesca de Palafolls, el 17 de setembre de 1425, al moliner Narcís Plana, des del primer d'octubre vinent fins al primer de gener de 1427; però fou cancel-lat el 12 d'octubre per voluntat de les dues parts ${ }^{19}$.

La sèrie de protocols notarials de Jonqueres que guarda l'Arxiu de la Corona d'Aragó dóna notícia dels arrendaments successius, gairebé sempre reduïda a una nota marginal sobre una pàgina en blanc. El volum 173, del notari Joan Ubach, força mal conservat i sense foliació, ens informa del següent:

El 27 de febrer de 1433, la priora Serena de Cabanyelles arrenda el molí al moliner Pere de Luna, per tres anys, des del primer de març vinent, per 16 lliures anuals, de les quals pagaria 26 sous 8 diners el mes. Havia de

\footnotetext{
${ }^{18}$ ACA, C, reg. 1282, fols. 64-65.- J. MUTGÉ I VIVES, Les drassanes de Barcelona en temps d'Alfons el Benigne i de Pere el Cerimoniós," Història urbana del Pla de Barcelona". Actes del II Congrés d'Història del Pla de Barcelona, vol. 1, Barcelona, 1989, pp. 303-314.

${ }^{19}$ Arxiu Històric de Protocols de Barcelona, notari Joan Ubach, lligall 1, manual 5, anys 1424-1426.
} 
moldre el blat necessari per al convent, pagar la dècima (que pagaven per tot el blat mòlt a la sagristia de la seu de Barcelona) i un terç de les despeses dels aparells. El monestir no estava obligat a pagar res per cap incident fortuït, per falles d'aigua, etc. Tampoc no durà gaire aquest arrendament, ja que el 16 de febrer de 1434 la priora Isabel de Gualbes en feia un altre al moliner Andreu Metge ${ }^{20}$.

Del mateix notari és el volum 174 , ja amb folis numerats d'origen:

-fol. 4v: La priora Isabel de Gualbes arrenda el molí a Pere Gurri, 14 de gener de 1435 .

-fol. 27: Simó Martorell, prevere, procurador i ecònom en nom de la mateixa priora, l'arrenda a Pere Gener, 24 de gener de 1439.

-fol. 32: Simó Martorell l'arrenda a Pere Gurri, 30 de desembre de 1440.

-fol. 42v: Simó Martorell l'arrenda a Antoni Serrat, 26 d'octubre de 1440 .

Tots aquests documents tenen la pàgina de text en blanc. Solament n'hi ha un de més explícit, al fol. 68v:

Simó Martorell arrenda el molí (és a dir, els drets que hi té el convent) per un any a Pere Coll, mercader, de Barcelona, per 30 lliures barcelonines, de les quals en pagaria immediatament 13 lliures 15 sous i, a la fi de cada mes, 27 sous 1 diner fins a completar les 16 lliures 5 sous restants. Havia de moldre el blat que necessitessin els dos monestirs i pagar la dècima a la seu i la quarta part de les despeses dels aparells que s'especifiquen llargament. També havia d'escurar el rec i la bassa del molí. I procurar fer la farina bona, sota la inspecció del mateix Martorell i de l'administrador dels molins reials de Barcelona. I si el monestir de Pedralbes no estava d'acord amb l'arrendament, calia que es fes una concòrdia amb el seu procurador sobre la part que els en tocava ${ }^{21}$.

En el volum 175, del notari Bartomeu Costa major, hi figuren els següents arrendaments fets per Bartomeu Negre, procurador del monestir:

-fol. 62v: A Pere Artigues, moliner, per dos anys, des de la data de l'arrendament, a 1 lliura el mes. Les condicions són les mateixes del document que abans hem esmentat.- Primer de maig de 1453.

\footnotetext{
${ }^{20} \mathrm{ACA}$, ORM, U, vol. 173.

${ }^{21}$ ACA, ORM, U, vol. 174, fols. 4v, 27, 32, 42v, 68v.
} 
-fol. 73v: A Jaume Planes i Antoni Font, per cinc anys, des del primer d'agost passat.- 7 d'agost de 1453.

I finalment, en el volum 177, fol. 16:

A Antoni Padragós, moliner, per cinc anys, a 15 ll. l'any (a pagar 25 sous cada mes).- 28 de febrer de $1459^{22}$.

Del volum 180 del mateix notari Bartomeu Costa hem extret les següents notícies referents a obres del molí:

-fol. 7v-8: El 29 d'octubre de 1477 acusen rebut a Bernat Puig, prevere, procurador del monestir de Jonqueres, els operaris següents:

Joan Buadella, fuster, per fustes i per jornals de les seves obres.

Guillem Arbonés, mestre d'obres, per rajoles, teules, calç, guix, argila, lloguer de travesses, de portadora, de galledes, etc.

Pere Esteve Soler, traginer, per jornals de 36 homes que escuren la bassa del molí i per esbardissar el rec sota el molí, etc.

Joan Palou, courer, per plom, etc.

-fol. 95: Joan Buadella, fuster, per fer les portes del molí.- 29 de gener de 1481 .

-fol. 154: Joan Bastida, moliner, el 15 de juny de 1482, per set mesos de la seva soldada i per despeses d'escurar el rec i herbejar, des del primer de juny fins al 31 de desembre de 1478 .

-fol. 154v: el mateix pels anys 1579 i 1480.

-fol. 155: el mateix pel 1481 .

-fol. 177: segons un rebut del notari Costa al procurador Puig, consta, entre altres coses, que ell va fer els documents de l'arrendament del molí el 20 de març de 1477 (sense altres dades) ${ }^{2.3}$.

Prop del molí, el monestir hi tenia encara algunes terres. Així, la priora Agnès Romeu i el convent de Jonqueres, el 16 d'octubre de 1477, van establir a Pere Pons, canviador i mercader, de Barcelona, un tros de terra tancat de parets, amb dos portals i amb arbres, més enllà del coll de la Celada, on hi havia hagut l'antic monestir. El cens era de 18 sous barcelonins. Aquest Pere Pons, juntament amb Isabel, vídua de Pau Vida, va tenir un plet amb les monges i el va perdre, com també va perdre l'apel·lació, per una sentència de 8 d'agost de 1478; la sentència la confirmà Pere Vicens, administrador de les aigües del rec Comtal, el 2 de gener de 1481. Els

\footnotetext{
"2ACA, ORM, U, vol. 175, fols. 62v, 73v; vol. 177, fol. 16

${ }^{23} \mathrm{ACA}$, ORM, U, vol. 180, fols. 7v-8, 95, 154, 154v, 155. 177.
} 
perdedors havien de deixar lliure per al monestir un espai al final de les terres que ells tenien contigües al rec del molí d'en Carbonell, a fi de poder netejar el mateix rec. Passaren alguns anys i aparegué Benet Pons, mercader de Barcelona, probablement successor de Pere Pons. Benet, el 18 de març de 1522, va vendre a Miquel Puig, hortolà, un tros de terra que fou hort, indubtablement el mateix abans esmentat, i que es tenia pel monestir a cens de 18 sous barcelonins anuals. El preu de venda fou de 120 lliures barcelonines. Tres dies després, Pons li confirmà la venda i li donà diverses garanties i fiadors ${ }^{24}$.

Amb la sagristia de la seu de Barcelona, el monestir de Jonqueres va tenir un plet perquè el convent devia, des de 12 anys enrera, la dècima que pagava sobre les mòltes. Els fou donat un termini de tres dies per a pagar el deute. El procurador va al-legar una certa ignorància per part del monestir i l'exempció que tenia la priora per privilegis papals. Necessitava temps per a cercar a l'arxiu monàstic els documents acreditatius i també per a demanar els que el mestre de l'orde tenia a Castella. El temps no li fou concedit perquè la sagristia tenia proves suficients de la seva pròpia raó. La sentència del jutge Jaume Buguera, el 10 de març de 1481, va condemnar el monestir a pagar, i ho confirmà una posterior sentència de la causa d'apel lació ${ }^{25}$.

Les qüestions entre Pedralbes i Jonqueres no havien acabat mai del tot. El 27 de febrer de 1532, Teresa de Cardona, abadessa, i Elisabet de Malla, priora, respectivament, dels dos monestirs, van arribar a una concòrdia. Tot havia començat el 3 de gener de 1498, quan el procurador de Pedralbes va reclamar a Jonqueres 12 lliures per la meitat del lloguer del molí, que feia quatre anys que no els l'havien pagat. Suposem que, més que del lloguer, es devia tractar dels fruits o rendes. Jonqueres va respondre que, certament, corresponia a Pedralbes la meitat dels fruits del molí, però abans s'havien de deduir les despeses i calia que ells es retinguessin el que pagaven per la dècima a la sagristia de la seu: la resta seria la que es dividiria en dues parts. Pedralbes estava d'acord amb deduir les despeses, però no amb la dècima, que ells no havien pagat mai. Jonqueres presentà un compte de 210 lliures 15 sous i 6 diners que havien donat per dècima fins a la fi de 1498 i volia que Pedralbes els en pagués la meitat. En fi, les discussions foren molt llargues i van acabar amb la concòrdia del 1532. Pel que es veu,

\footnotetext{
${ }^{24}$ ACA, ORM, U, pg. J.295, J.321, J.350, J.323.

${ }^{25} \mathrm{ACA}, \mathrm{ORM}, \mathrm{U}$, document en paper unit al pg. J.503.
} 
Jonqueres havia donat a Pedralbes les 12 lliures reclamades. Vist això, ara havia de donar-los 150 lliures pel que haurien valgut els fruits des del 3 de gener de 1498 fins a la fi del 1531: a pagar 50 lliures des del Nadal passat i per tot l'any present, 50 més pel Nadal del 1534 i altres 50 pel del 1535 . Des d'ara, Pedralbes pagaria la meitat de la dècima i, deduïda aquesta i les despeses, els fruits restants es dividirien. A més, Pedralbes es comprometia a no demanar res més sobre els fruits anteriors al 1531, i tampoc sobre danys rebuts ni plets d'aquell període. Jonqueres renunciava a promoure causes amb l'altra part, i a cridar-la a judici. En els arrendaments es faria com fins ara: el moliner moldria forment per als dos monestirs, i així ho juraria al procurador de Pedralbes ${ }^{26}$.

Entre el 1679 i el 1695 va tenir lloc un plet entre els tutors i curadors dels fills de Jacint Gelabert i Rabassa, d'una part, i de l'altra Josep Cuquet, prevere i beneficiat de Santa Maria del Mar, i Caterina Llinàs i Ferell, vídua, sobre la senyoria d'un tros de terra al coll de la Celada que els dits tutors tenien sota el domini de la priora i convent de Jonqueres. No podem assegurar que sigui precisament la terra que fou dels Pons, però almenys dóna constància del domini del monestir en aquells indrets ${ }^{27}$.

Aquest domini el demostren també dues relacions de les rendes que rebia el monestir entre el 1686 i el 1689. L'autor de la primera, el procurador Josep Comerma, diu que tenien un molí comú amb Pedralbes, "del qual antes espallar la pedra y nivell se· $n$ treia uns anys ab altres per quiscun de dits convents, pagats tots gastos, unas $125 \mathrm{ll}$., pero ara estant com esta en los presents comptas se veura lo que se.n ha tret, que rellevat lo celari del moliner no crech importa tant y encara se ha de tenir grandissim treball en trobar qui vulle anar a molrer a dit moli y iudico que pagats tots gastos ne traura cada convent quiscun any unas 7511 ." La segona relació, datada el 1688, insisteix en el mal estat, agreujat per l'avaria de la pedra, del molí d'en Carbonell, "lo qual antes de romprer la pedra y lo nivell se arrendava a 300 ll. per any, y pagats tots gastos y la part del monestir de Pedralbes y la farina franca per Jonqueres, ne quedaven uns anys ab altres 12 11. poch mes o menos; empero ara, per haver $\mathrm{i}$ poca aygua y haver de

\footnotetext{
${ }^{26} \mathrm{ACA}, \mathrm{ORM}, \mathrm{U}, \mathrm{pg} . \mathrm{J} .503$.

${ }^{27} \mathrm{ACA}, \mathrm{ORM}, \mathrm{U}, \mathrm{J} .336$ (procés en paper). V. també ORM, U, lligall 163.
} 
tenir majordom en dit moli, al qual se ha de pagar al menos 9 ll. cada mes, es cosa lo que se'n traura de 6011 . a 70 ll. per any"28.

Malgrat tot, els arrendaments del molí van continuar. Del segle XVIII es conserven, en plecs o quaderns separats, els següents:

A Pere Francesc, moliner, des del 18 de juny de 1769, per 3 anys, a 308 lliures 6 sous 8 diners l'any.- 24 de març de 1770 .

A Josep Ferrater, des del 18 de juny de 1775, per 3 anys, a 343 lliures 16 sous 8 diners l'any.- 20 de gener de 1776 .

A Jacint Massana, comerciant, des del 18 d'octubre de 1778, per 3 anys, a 383 lliures 6 sous 8 diners l'any.- 30 de març de 1779 .

A Ramon Isaura, brodador, des del 18 d'octubre de 1781, per 3 anys, a 450 lliures l'any.- 29 d'agost de 1781.

A Jaume Gibert, moliner, des del 18 de maig de 1792, per 5 anys, a 490 lliures 3 sous 8 diners l'any.- 26 d'abril de 1792 .

Curiosament, un altre arrendament fet el 22 de juliol de 1792 tornava el molí a Josep Ferrater, comerciant, per 3 anys, des del 18 de juny anterior, a 276 lliures 6 sous 8 diners l'any. Tal vegada no va tenir efecte, perquè sembla que hi ha una continuitat de Jaume Gibert en l'ofici. Aquest, passats exactament els seus cinc anys, obté un nou contracte el 31 d'octubre de 1797, per altres 5 anys a comptar des del 18 de maig darrer, a 600 lliures l'any. I el 30 d'abril de 1802 li fou renovat encara, per cinc anys més, també des del 18 de maig del mateix any, a 655 lliures 8 sous l'any.

En tots aquests arrendaments es van repetint les mateixes condicions, la mateixa dependència del monestir de Jonqueres, el qual té el molí "comunament i per indivís amb l'abadessa de Pedralbes", i la situació del molí, a la parròquia de Sant Martí de Provençals, passat el paratge on era la creu de Sant Francesc i avui el Fort Pius, a la vora del camí ral.

El 1808, amb la guerra, va arribar la desfeta del monestir de Jonqueres. Les poques monges que hi vivien van haver d'abandonar l'edifici i dispersar-se cap a altres allotjaments. Però per bé que no retornaren a l'antiga casa, la personalitat del convent va continuar existint durant alguns anys i sempre hi hagué algú que procurava la conservació de les rendes que encara quedaven. Així, doncs, el 28 d'agost de 1817, fou un advocat el qui, actuant en nom del procurador de la subpriora, vacant el priorat, va arrendar el molí d'en Carbonell, per 3 anys, des del dia primer del mateix mes, i per

\footnotetext{
${ }^{28} \mathrm{ACA}, \mathrm{ORM}, \mathrm{U}, \mathrm{J} .635, \mathrm{~J} .636$ (documents en paper).
} 
650 lliures l'any, a Francesc Gibert, moliner, possible familiar de l'anterior arrendatari. Passats els tres anys, el 6 de desembre de 1820, l'administrador de les monges va fer un nou contracte a Gibert per 3 anys més, a $500 \mathrm{ll}$. l'any, a comptar des del primer d'agost darrer. I la sèrie d'arrendaments fins ara coneguts acaba amb el que fou fet a l'esmentat Gibert per Josep Alier i Carbó, administrador en propietat dels béns, rendes i drets corresponents al monestir, que havia estat declarat extingit perquè les monges no s'havien tornat a reunir com a comunitat. Alier figurava com a administrador únic, per bé que el molí depenia encara d'alguna manera dels dos monestirs. L'arrendament era per 5 anys, des del primer de gener de 1824 , a 500 lliures l'any. El contracte fou datat el 29 d'abril de 1824 . És, cronològicament, l'últim record que tenim del vell molí d'en Carbonell, tan lligat a l'història del segon monestir de Jonqueres ${ }^{29}$.

\section{RÉSUMÉ}

L'Ordre militaire de Saint Jacques, au XIII ${ }^{\text {eme }}$ siècle, eut le premier monastère féminin de Sainte Marie de Jonqueres près de Sabadell. Avec l'autorisation du roi Jacques I, Pere Carbonell bâtit un moulin extra-muros de Barcelone. Le roi céda son droit et son domaine sur le moulin au Maître du susdit Ordre et permit la construction, tout près de celuilà, d'un deuxième monastère pour les dames de Jonqueres. Bientôt, en 1300, à cause de l'insalubrité de l'endroit, elles ont passé à leur troisième monastère, dans la ville. Elles continuèrent à exercer le domaine sur le moulin, comme l'avait exercé leur Maitre. Mais lorsque le monastère de Pedralbes fut édifié, les deux communautés ont joui de ce domaine par indivis. On divisait les rentes et les fruits à moitié. Le moulin, depuis le $\mathrm{Xv}^{\text {ème }}$ siècle, fut affermé à des meuniers. Il y eut plusieurs litiges et procès entre les deux couvents et aussi des concordes, comme celle de 1532. A cause de la guerre, en 1808, les réligieuses de Jonqueres abandonnèrent à jamais leur monastère. Pourtant leurs administrateurs ont continué les louages du moulin, au moins jusqu’à 1824 .

\section{SUMMARY}

The first feminine monastery of Jonqueres, belonging to the military Order of Santiago, was constructed near Sabadell, in the XIItth century. By king James I authority, Pere Carbonell built a mill outside the walls of Barcelona. The king granted his dominion over the mill to the Master of the mentioned Order and allowed the construction, close to the

\footnotetext{
${ }^{29} \mathrm{ACA}, \mathrm{ORM}$, sèrie Hisenda, lligall 375.
} 
same mill, of a second monastery for the Jonqueres community. Because of the place insalubrity, they soon moved to a third monastery inside the city. The nuns had the dominion over the mill as once the Master had. But when the monastery of Pedralbes was built, both monasteries enjoyed indivisibly that right. The mill, from the XVth century, was rented to some millers. Rents and profits were divided in equal parts. There were several lawsuits between the two convents and also there were some agreements, as in 1532 . Because of the war, in 1808 , the Jonqueres nuns left their monastery forever. Nevertheless, their managers kept renting the mill at least until 1824 . 